\title{
An evaluation of professional quality measurement systems for the automotive industry
}

\author{
Ozge Senoz $^{1}$, William Daughton ${ }^{2}$, Abhijit Gosavi ${ }^{3}$, Elizabeth Cudney ${ }^{4}$ \\ ${ }^{1,2,3,4}$ Department of Engineering Management \& Systems Engineering, Missouri University of Science and Technology, USA
}

\begin{abstract}
This paper presents data from two sources for the current state of quality, reliability, and safety in the automobiles produced in the US and some major Asian companies. These two major sources, Consumer Reports and J.D. Power and Associates are evaluated in terms of the kind of information they present, the way they collect their data, and what they measure. The focus has been placed on these sources because they are the two leading authorities in terms of the amount of data and research they have in store. The result of the analysis provides a perspective on the magnitude and value of the information provided by these sources. The ultimate goal of this study is to get comparable quantitative information about automobile quality manufactured by the U.S. Big Three and their Asian counterparts. This data and information, based on the two sources mentioned above, will identify how the U.S. Big Three compare today to the Asian manufacturers. In addition, data compiled from the last 10 years will show the relative improvement of these competitors in the areas of quality, reliability, and safety.
\end{abstract}

Keywords: Quality, automobile, reliability, safety

\section{Introduction}

The popular media is rich with advertisements claiming that the U.S. manufacturers have closed the historical gap in quality, reliability, and safety with their Asian counterparts (Bradsher, 2000). However, it is difficult to separate real fact from marketing license with the information. A guiding quality principle of fact-based decision making suggests that a more comprehensive study of the comparative performance of the U.S. and Asian automobile manufacturers is warranted. In this study two major sources of information on quality, reliability, and safety have been examined to determine their suitability for such comparisons. Consumer Reports (CR) and J. D. Power and Associates (JDP) provide potentially valuable information appropriate for this comparison, and the approaches, methodologies, and critique of them will be examined herein.

Consumer Reports (CR) and J. D Power and Associates (JDP) have been providing information on automobile quality, reliability and safety since 1936 and 1968 respectively. Countless consumers have relied on these two sources of information to make buying decisions on both new and used cars. The extent and depth of coverage have evolved over the years to address nearly every aspect of an automobile. CR is one of the top-ten-circulation magazines in the country and is published by the independent nonprofit organization, Consumers Union. The mission of Consumers Union (CU) is to work for a fair, just, and safe marketplace for all consumers. In addition, CU does not accept outside advertising to maintain its independence and impartiality. JDP is a global marketing information firm that conducts surveys of customer satisfaction, product quality and buyer behavior. JDP states that its rankings reflect the opinions of consumers only. Like CR, in order to stay impartial and deliver unbiased results, JDP funds all of its own syndicated research.

CR reliability ratings attempt to show how well vehicles have held up compared with other models and how likely it is that an owner will face problems and repairs. The data come from annual surveys of approximately 7 million magazine and web site subscribers. Similarly, JDP provides the information it collects from surveys in what is called the Power Circle Ratings (2011). All Power Circle Ratings are based on the opinions of a sample of consumers who have used or owned the product or service being rated. 
The surveying approaches of the two organizations are significantly different. The Consumer Reports National Research Center sends out The Annual Auto Surveys (2011) to a random sample of the several million readers who subscribe to Consumer Reports or to consumerreports.org. These surveys are not commissioned or financed by industry. They offer detailed information on approximately 300 models each year by asking the respondents about any serious problems they have had with their vehicles in the preceding 12 months in 17 trouble areas. Based on the information gathered from the surveys, a reliability history is created for each model for the last 10 years. Consumer Reports makes forecasts about the upcoming year's model based on that reliability data. The surveys also ask owners how satisfied they were with their vehicle and whether they would buy that vehicle again.

Korsch (2007) questions the geographical profile of the CR readership and states that it appears dense on the two U.S. coasts and less dense in the heartland and the Deep South. He also has suspicions about basing the ratings on self-selected responses such as CR's ownership satisfaction polls. An article in The New York Times by Timothy Noah (1999) draws attention to the different incentives of these two entities when it comes to the rankings they publish. He says JDP is gaining in visibility, because unlike JDP, CR does not allow its ratings to be publicized by advertisers. Also, CR does not advertise. JDP uses advertisements to raise its own profile with the public, which in turn helps J.D. Power attract more corporate clients who buy copies of its syndicated studies, commission it to do proprietary studies or both. Noah continues by stating that this symbiotic relationship inhibits JDP in some ways compared to CR. JDP mostly stopped releasing unfavorable rankings to the public except to the corporate buyers of the syndicated surveys. This was due to the adverse reactions given by the poor performers' manufacturers after seeing that the press was putting emphasis on bad news. So JDP instituted a policy where only above-average rankings in syndicated studies were made public. Companies that rank below average are listed alphabetically in press releases. As a result, consumers get information about what JDP likes, but not about what it does not like.

CR buys and tests about 80 vehicles per year at their independent automobile testing center. Each vehicle is driven for thousands of miles and goes through more than 50 individual tests. Some of these tests are objective, which yield empirical results; yet some are subjective evaluations done by the engineering staff. Murray (2007) states that Consumer Reports' automotive test facility has become recognized as the best in the world at automotive evaluation and has extraordinary influence over the car-buying public. At the testing site, the small engineering staff does what no one else in the car evaluation business even tries. It runs vehicles through a battery of 50 performance tests, then matches those results up against data from 1.3 million car owners, the better to tell whether a vehicle's initial performance matches up against its long-term reliability. Also, wherever possible, subjectivity is removed from performance tests.

JDP collects survey responses through 5 different studies: Initial Quality Study (IQS), Vehicle Dependability Study (VDS), Automotive Performance, Execution and Layout Study (APEAL), Customer Service Index (CSI), and Sales Satisfaction Index (SSI). For the IQS, survey respondents provide feedback on quality of their new vehicles during the first 90 days of ownership. They are asked about mechanical quality indicators like defects and malfunctions; and design quality indicators such as how well a particular feature works or operates. The study examines 217 vehicle attributes. For the APEAL study, JDP surveys thousands of new vehicle owners by asking them about their purchase experience, their vehicle's quality, service experience at the dealer, and what they like and dislike about the new vehicle after 90 days of ownership. JDP also surveys owners of 3-year-old vehicles that were purchased new and asks them to identify problems that have arisen in the previous 12 months in any of 200 areas to conduct the VDS. Unlike CR, JDP does not test vehicles. Newman (2004) wrote that virtually all automakers today buy some of JDP data. However, they complain that the rankings oversimplify the quality issue. For example, in the new car quality survey, a car's basic attributes, gas mileage, and the placement of cup holders are lumped in with problems like rattles, buzzes, and broken equipment. Carmakers believe the survey should measure only the defects. Newman points out that some auto executives argue that outlets such as Consumers Union, which exhaustively test and evaluate cars, provide better information than opinion surveys. He adds, however, that the discomfort JDP causes the industry clearly indicates a degree of success. According to Whitney [13], in the world of automotive industry research, nothing makes for more entertaining reading than the reports of U.S.-based business sector analyst J. D. Power and Associates. He continues by stating that JDP's ratings of automobiles are awaited by manufacturers with a mixture of fear and hope and many a board of directors has been pruned following a poor showing in these prestigious reports. Timothy Noah (1999) of The New York Times, however, talks about how survey research is not infallible and adds that J.D. Power's minimum sample size for automotive surveys -- 250 responses per car model -- allows for a margin of error around 6 percent. He asks even if we assume JDP's surveys accurately reflect public opinion, does that public really know what it's talking about. He writes: "Alternatively, it may be that the sort of people who do fill out questionnaires -- the same folks who go through life sending their steak back because they wanted it medium well, not medium -- skew J.D. Power's survey not toward intelligent criticism, but toward querulous complaint. People who care too much about being satisfied customers do not necessarily have a tighter grip on reality than people who care too little, like me” (Noah, 1999).

\section{Evaluations and Scoring}

2.1 Reliability evaluations: The data from the CR survey responses are compiled to to construct Reliability Histories on several hundred makes and models of cars, minivans, pickups, and SUVs, spanning 10 model years. The Reliability History Chart shows whether a particular model has had more or fewer problems than the average model of that year in each of 17 trouble spots. The 
Used Car verdict is the summary of the 17 trouble spots for the model each year going back 10 years. It also includes the comparison of that model to the average of all vehicles in the same model year. The 17 trouble spots that are rated are:

1. ENGINE MAJOR: Engine rebuild or replacement, cylinder head, head gasket, turbocharger or supercharger and timing chain or belt.

2. ENGINE MINOR: Oil leaks, accessory and pulleys, engine mounts, engine knock or ping.

3. ENGINE COOLING: Radiator, cooling fan, water pump, thermostat, antifreeze leaks, overheating.

4. TRANSMISSION (AND CLUTCH)-MAJOR: Transmission rebuild or replacement, torque converter, premature clutch replacement.

5. TRANSMISSION (AND CLUTCH)-MINOR: Gear selector and linkage, coolers and lines, transmission computer, transmission sensor or solenoid, clutch adjustment, hydraulics [clutch master or slave cylinder]; rough shifting, slipping transmission.

6. DRIVE SYSTEM: Driveshaft or axle, CV joint, differential, transfer case, four-wheel-drive/all-wheel-drive components, driveline vibration, electrical failure.

7. FUEL SYSTEM: Check-engine light, sensors (O2 or oxygen sensor), emission-control devices (includes EGR), fuelinjection system, engine computer, fuel cap, fuel gauge/sender, fuel pump, fuel leaks, stalling or hesitation.

8. ENGINE ELECTRICAL: Starter, alternator, hybrid battery and related system, regular battery, battery cables, engine harness, coil, ignition switch, electronic ignition, distributor or rotor failure, spark plugs and wires failure.

9. CLIMATE SYSTEM: A/C compressor, blower (fan) motor, condenser, evaporator, heating system, automatic climate system, electrical failure, refrigerant leakage.

10. SUSPENSION: Shocks or struts, ball joints, tie rods, wheel bearings, alignment, steering linkage [includes rack and pinion], power steering (pumps and hoses, leaks), wheel balance, springs or torsion bars, bushings, electronic or air suspension.

11. BRAKES: Antilock system (ABS), parking brake, master cylinder, calipers, rotors, pulsation or vibration, squeaking, premature wear, failure.

12. EXHAUST: Exhaust manifold, muffler, catalytic converter, pipes, leaks.

13. PAINT/TRIM/RUST: Paint (fading, chalking, peeling or cracking), loose exterior trim or moldings, rust.

14. BODY INTEGRITY (Squeaks or rattles): Seals, and/or weather stripping, loose interior trim and moldings, air and water leaks, wind noise.

15. BODY HARDWARE (Power or manual): Windows, locks and latches, doors or sliding doors, tailgate, trunk or hatch, mirrors, seat controls (movement and temperature), seat belts, sunroof, convertible top, glass defects.

16. POWER EQUIPMENT AND ACCESSORIES: Cruise control, clock, warning lights, body control module, keyless entry, wiper motor or washer, tire pressure monitor, interior or exterior lights, horn, gauges, $12 \mathrm{~V}$ power plug, alarm or security system, remote engine start.

17. AUDIO SYSTEM [excluding aftermarket systems]: radio, speakers, antenna; cassette, CD, or DVD player; video screen, iPod \& MP3 interface; SYNC, OnStar, Bluetooth; navigation system (GPS), backup camera/sensors.

Each of the 17 problem areas in the survey covers an array of possible breakdowns. For instance, "Power Equipment" includes keyless entry, dashboard warning lights, tire-pressure monitor, and other things. "Body integrity" includes squeaks and rattles, seals and weather stripping, and air or water leaks, among other things. "Major Engine" problems include cylinder head and timing belt besides replacing the engine itself, while "Minor Engine" includes oil leaks, accessory belts and engine mounts. In addition, problems with the engine-major, cooling system, transmission-major, and driveline are weighed more heavily in CR's calculations of Used Car Verdicts and Predicted Reliability because those areas are more expensive to repair than others. CR's Predicted Reliability rating for new cars is a measure of how well a new model is likely to hold up based on the model's recent history, provided the model has not been significantly redesigned for the current model year. To calculate this rating, Consumer Reports averages a model's Used Car Verdict for the newest three years. Predicted Reliability is shown in the Reliability History Charts as the New Car Prediction.

The structure of main sections can be built in a ways that strengthen the concept of manuscript. The first of these supporting methods is the adoption of good, descriptive headings of sections and subsections. The choice if these headings are important because well-chosen headings are not only an aid to the reader but also a reminder to the author(s) to keep in focus the content of each section. Illustrations and tables enhance the quality of presentation.

2.2 J.D. Power and Associates: To obtain its Reliability Ratings, J.D. Power uses the Vehicle Dependability Study (VDS). For example, in conducting the 2010 VDS, original vehicle owners were asked to report the type and number of problems they experienced during the preceding 12 months with their 3-year-old vehicle. Predicted Reliability information is derived from the Initial Quality and Vehicle Dependability Studies and is a forecast of how reliable a newer vehicle might be over time. The areas that are rated are:

1. OVERALL DEPENDABILITY: Taken from the Vehicle Dependability Study (VDS), which looks at owner-reported problems in the first 3 years of new-vehicle ownership, this score is based on problems that have caused a complete 
breakdown or malfunction of any component, feature, or item [i.e., components that stop working or trim pieces that break or come loose].

2. POWERTRAIN DEPENDABILITY: Taken from the Vehicle Dependability Study (VDS), which looks at ownerreported problems in the first 3 years of new-vehicle ownership, this score is based on problems with the engine or transmission as well as problems that affect the driving experience (i.e., vehicle/brakes pull, abnormal noises or vibrations) only.

3. BODY AND INTERIOR DEPENDABILITY: Taken from the Vehicle Dependability Study (VDS), which looks at owner-reported problems in the first 3 years of new-vehicle ownership, this score is based on problems with wind noise, water leaks, poor interior fit/finish, paint imperfection, and squeaks/rattles.

4. FEATURE AND ACCESSORY DEPENDABILITY: Taken from the Vehicle Dependability Study (VDS), which looks at owner-reported problems in the first 3 years of new-vehicle ownership, this score is based on problems with the seats, windshield wipers, navigation system, rear-seat entertainment system, heater, air conditioner, stereo system, sunroof and trip computer.

Unlike JDP, CR's reliability ratings are grouped under 17 problem areas. For example, instead of one rating for "powertrain dependability," CR lists and rates five areas that are related to powertrain: engine, transmission, brakes, drive system, and suspension. For "body and interior dependability" rating, CR provides ratings for body integrity and paint/trim/rust. Finally, for the "feature and accessory dependability" area, CR has the ratings for the climate system, power system and accessories, body hardware, and audio system.

2.3 Quality evaluations: The significant difference between the two sources is that CR makes its own initial new car quality evaluations through road tests and other calculations; whereas JDP surveys new vehicle owners within the first 90 days of ownership to gather quality information. CR comments on the JDP system briefly at consumerreports.com, and states that JDP covers only the first three months of ownership, a period in which relatively little goes wrong. It also asks owners about many subjective impressions of their vehicles, not just serious problems they've had [2]. Automotive News senior writer Jesse Snyder [16] comments on JDP's IQS methodology by saying that over the years, critics have griped about J.D. Power's methodology -not a random sample and too-small samples on less popular models -- and policies, such as placing equal numerical weight on blown engines as on vibrating ash trays. His reply to these critics is: "I say, so what?". He continues: "For all its flaws, the data are the best available. And the IQS has driven continuous improvement in vehicle quality for years, acting as both carrot and stick. Automakers grumble, but they work very hard to improve their scores. And they pay J.D. Power for the right to use its name and endorsement on their advertising”.

CR provides summary information on quality through its Model Summary including a note of Recommended Vehicles. In order to earn a CR Recommendation, a model needs to meet three criteria: The model needs to do well in their road tests, the model must have at least average Predicted Reliability, and if the model was crash-tested by the National Highway Traffic Safety Administration (NHTSA) or the Insurance Institute for Highway Safety (IIHS), it must perform at least adequately. In addition, pickups and SUVs must not have tipped up in the government's rollover test or, if not tested, must be available with electronic stability control (ESC).

The last rating is also based on crash test results performed by the U.S. Government and the insurance industry. Vehicles are rated by category with an Overall Score for comparative purposes. The overall score for a tested model is based on CR's results from more than 50 tests and evaluations. On the other hand, JDP quality ratings come from its Initial Quality Study (IQS), which surveys owners of new vehicles in the first 90 days to obtain information on 217 vehicle attributes. This study divides consumerreported problems into two main categories: Malfunctions/Defects, and Design issues. The JDP summary information includes an Overall IQS Score based on problems that have caused a complete breakdown or malfunction and quality scores based on specific problems in mechanical, power-train, interior areas, accessories, and design features. CR does not conduct surveys to determine initial quality. It buys and tests about 80 cars per year and drives each for thousands of miles. The evaluation regimen consists of more than 50 tests and includes both subjective and empirical findings.

2.4 Performance evaluations: The information comes from the Consumer Reports test data for the vehicle and any related versions tested and provides evaluation of:

1. ACCELERATION: Acceleration runs are made from a standstill with engine idling.

2. TRANSMISSION: Transmission performance is determined by shifting smoothness, response, shifter action, and clutch actuation for manual transmissions.

3. ROUTINE HANDLING: This judgment reflects how agile the vehicle is on the road by the amount of body lean and steering response. Also reflects turning circle.

4. EMERGENCY HANDLING: This judgment reflects how the vehicle performed when pushed to its limits on the track and in the CR emergency-avoidance maneuver.

5. BRAKING: The braking judgment is a composite of wet and dry stopping distances, resistance to fade, as well as pedal feel and directional stability. 
6. RIDE: The ride judgment is determined by how well the suspension isolates and absorbs road imperfections and how steady it keeps the body on various road surfaces.

7. NOISE: This judgment is a composite of several instrumented measurements as well as subjective evaluation in normal driving.

8. DRIVING POSITION: Driving position shows how well drivers of various heights are situated in relation to the controls and their visibility.

9. FRONT, REAR, AND THIRD SEAT COMFORT: These are determined by a jury evaluation of various sized testers.

10. FRONT, REAR, AND THIRD ACCESS: Measure of how easy it is to enter and exit the cabin.

11. CONTROLS AND DISPLAY: Measure of clarity and intuitiveness.

12. INTERIOR FIT AND FINISH: An evaluation of the interior quality and craftsmanship.

13. TRUNK/CARGO AREA: Judged by the amount of luggage they can accommodate.

Climate system and Fuel economy data are also provided. Korsch (2007) believes that Consumer Reports is thinner on specifications and performance data than it was 40 years ago. He contends it never published a car's top speed, which is legitimate data.

The JDP Automotive Performance, Execution and Layout Study (APEAL) provides data about new vehicles after 90 days of ownership. It is based on eight categories of vehicle performance and design: engine/transmission; ride, handling and braking; comfort/convenience; seats; cockpit/instrument panel; heating, ventilation and cooling; sound system; and styling/exterior. However, the scores are grouped under these categories: Overall performance and design, performance, comfort, features and instrument panel, style.

1. PERFORMANCE is based on owner satisfaction with the vehicle's powertrain and suspension systems. These include acceleration, fuel economy, handling stability, braking performance, and shift quality.

2. COMFORT is based on owner satisfaction with the vehicle's comfort and convenience features and seats.

3. FEATURES AND INSTRUMENT PANEL component is based on owner satisfaction with the vehicle's stereo system, instruments, and climate system.

4. STYLE is based on owner satisfaction with the vehicle's interior and exterior styling, uniqueness of styling, exterior and interior colors.

According to a PRNewswire report (Snyder, 2009), the APEAL Study is significant as it measures the passion owners have for their cars, including their delight with the design, content, layout and overall driving performance of their new vehicles. Another article at PRNewswire says the closely watched APEAL Study survey measures customer satisfaction in design, content, and vehicle performance. Customers rate their level of "gratification" on a variety of vehicle attributes, including safety, fuel economy, cargo space, roominess and exterior styling. The article also quotes Ford's group vice president, Bennie Fowler, who said it was a significant accomplishment to do so well in APEAL on the heels of receiving high marks from JDP on initial quality (Noah, 1999).

CR provides more detailed ratings in the performance category. For instance, under performance evaluation, where JDP gives one rating, $\mathrm{CR}$ divides that into acceleration, routine handling, emergency handling, braking, transmission, and ride. In the comfort category, CR rates various properties related to comfort: Driving position, front/rear/third seat comfort, driving position, and noise. For the 'features and instrument panel' category, CR also has one scoring grouped under 'controls and display'. Finally, instead of a single 'style' rating, CR has separate ratings for interior fit and finish, and trunk/cargo area.

2.5 Safety evaluations: CR gives data on availability of Antilock brakes, traction control, stability control, daytime running lights, tire pressure monitor, safety belts, and air bags for every model. In particular, crash and rollover tests results are provided from two independent crash tests. One of them is the National Highway Traffic Safety Administration (NHTSA), which is a branch of the Transportation Department (Consumers Union, 2006). The other is the Insurance Institute for Highway Safety; a safetyresearch group sponsored by the insurance industry (Flint, 2005). These two organizations conduct front and side-impact crash tests using their own methodologies. NHTSA also tests for rollover propensity and the IIHS evaluates rear-crash protection. NHTSA scores its tests using a scale of one to five stars; more stars mean safer cars. The IIHS uses a four-level scale: Poor, Marginal, Acceptable, and Good. In contrast, JDP gives safety ratings (i.e. the two government crash test results) for only the vehicles that were chosen for Power Steering Reviews. For a vehicle to make the Power Steering Reviews, it has to rank among the top 3 vehicles in its class in one of the ratings studies, has to have done well in the government crash tests, and finally has to rank top in the fuel economy ratings by the EPA.

\section{Summary and Table}

The two major sources of information, Consumer Reports and J.D. Power and Associates, on vehicle reliability, quality, and safety in the U.S. both have the same purpose of conveying information about the above factors. However, there are differences in how they collect their data, the amount of such data, and the way they present it. There are disagreements over the validity and value of the data as discussed above. Overall, it is seems that CR has much more detailed information and categorization about the 
vehicles it studies than JDP. Table 1 provides a summary of the major rating categories for both sources and how they differ from each other.

Table 1. Comparison of CR and JDP Vehicle Evaluations

\begin{tabular}{|c|c|c|}
\hline & Consumer Reports & J.D. Powers and Associates \\
\hline $\begin{array}{l}\text { Survey } \\
\text { Methodology }\end{array}$ & $\begin{array}{l}\text {-About } 1 \text { Million responses on } 300 \text { models } \\
\text {-Asks about problems in the past } \\
12 \text { months in } 17 \text { trouble areas } \\
\text {-History is compiled for } 10 \text { years } \\
\text {-Buys and tests } 80 \text { cars per year }\end{array}$ & $\begin{array}{l}\text { - Tens of thousands of responses } \\
\text { from } 5 \text { different studies } \\
\text {-Asks about problems in the first } 90 \\
\text { days for IQS; after } 90 \text { days for } \\
\text { APEAL study; and } 3 \text {-year-old } \\
\text { vehicles for the past } 12 \text { months for } \\
\text { VDS } \\
\text {-Do not test cars }\end{array}$ \\
\hline $\begin{array}{l}\text { Reliability } \\
\text { Evaluations }\end{array}$ & $\begin{array}{l}\text {-Reliability history chart showing problem } \\
\text { rates for a model spanning } 10 \text { years } \\
\text {-Covers and rates } 17 \text { trouble spots } \\
\text {-Predicted reliability rating for new cars }\end{array}$ & $\begin{array}{l}\text {-VDS collects data in nearly } 200 \\
\text { problem areas but rating are grouped } \\
\text { into } 3 \text { categories } \\
\text {-Predicted reliability rating for new } \\
\text { cars }\end{array}$ \\
\hline $\begin{array}{l}\text { Quality } \\
\text { Evaluations }\end{array}$ & $\begin{array}{l}\text {-Conducts own tests and evaluations } \\
\text {-Road tests, in-house empirical and } \\
\text { subjective evaluations } \\
\text {-Opinions in the 'model summary' } \\
\text { section }\end{array}$ & $\begin{array}{l}\text {-Ratings come from the IQS survey } \\
\text { responses asking about problems } \\
\text { within the first } 90 \text { days of new } \\
\text { vehicle ownership } \\
\text {-Problems are divided into } \\
\text { Malfunctions and Design issues }\end{array}$ \\
\hline $\begin{array}{l}\text { Performance } \\
\text { Evaluations }\end{array}$ & $\begin{array}{l}\text {-Information comes from the road test } \\
\text { data on: acceleration, transmission, routine } \\
\text { handling, emergency handling, braking, } \\
\text { ride, noise, driving position, front/rear/ } \\
\text { third seat comfort and access, controls and } \\
\text { display, fit and finish, trunk area, climate } \\
\text { system, and fuel economy. }\end{array}$ & $\begin{array}{l}\text {-Information comes from the APEAL } \\
\text { study data on: performance, comfort, } \\
\text { features and instrument panel, and } \\
\text { style. }\end{array}$ \\
\hline $\begin{array}{l}\text { Safety } \\
\text { Evaluations }\end{array}$ & $\begin{array}{l}\text {-Data on availability of Antilock brakes, } \\
\text { traction control, stability control, daytime } \\
\text { running lights, tire pressure monitor, safety } \\
\text { belts, and air bags } \\
\text {-Results from the two major crash tests: } \\
\text { NHTSA and IIHS. }\end{array}$ & $\begin{array}{l}\text {-Gives safety ratings as crash test } \\
\text { results and for only the vehicles that } \\
\text { are chosen for Power Steering Reviews. }\end{array}$ \\
\hline
\end{tabular}

Flint (2005) believes CR is unjustly dismissed and explains why people should not do that. He states that Detroit engineers and executives do not spend enough time in Hondas and Toyotas; they really do not understand how good they are. They always think the criticisms their products get are prejudiced. Detroiters insist their vehicles are constantly improving but nobody recognizes the changes. Flint (2005) adds; "CR does not create the trends, but it does make them understandable. The CR center tests four to six vehicles each issue, 11 issues a year. The 12th issue is all about automobiles. CR spends \$2 million a year buying new vehicles for testing and gets \$1.4 million back selling them afterwards. It's time to start paying attention to what CR is saying. Before it's too late" (Flint, 2005). On the contrary, Dodge (2007) thinks when it comes to American vehicles, Consumer Report's ratings border on cruelty. While he agrees that CR is the gold standard of auto ratings, he also believes that American and German vehicles are not that far behind their Japanese rivals. He then questions how CR comes up with those ratings. He talks about Murray's visit to CR's testing center and what he reported. To better understand the 50 performance tests vehicles undergo, Murray (2007) rode with the Testing Director and recorded his experiences. He claims that it is understood after that experience why CR, whose independence from the automakers is legendary, gets so much respect. Murray presents information on how Consumer Report's eight-person engineering team is attracting the top brass of the auto industry to its Connecticut-based facility. According to a Big Three insider, the importance of Consumer Reports is recognized most strongly at the highest levels of the automotive industry. He 
adds that they are no doubt the best in the business. Consumer Report's evaluations distinguish themselves from the others by their use of reliability data in conjunction with the performance tests. Some vehicles which perform very well on the track might fall flat when data from the survey respondents come in.

\section{Conclusions}

Both sources discussed here provide information that sheds light on the current state of quality, reliability, and safety of automobiles currently on the market in the U.S. The majority of data comes firsthand from the owners who used the vehicles for a specific amount of time. CR, however, goes further and includes data from its road tests conducted by experts in their fields. CR puts heavy emphasis on reliability issues and ratings related to that. It gives individual ratings on 17 trouble spots that vehicles may face. JDP, on the other hand, clusters these areas into fewer groups of ratings. But, both provide good insight about a particular model. JDP's quality ratings come from its Initial Quality Study and gives ratings on two major categories: mechanical issues and design issues. It is important to note that CR has no survey ratings in terms of quality, however, provides results and opinions based on their own road tests and evaluations. For safety, CR reports the results of two major crash tests NHTSA and IIHS, but JDP only reports those for the vehicles that made the Power Steering Reviews. In spite of the differences, both CR and JDP provide useful information on the current status of reliability, quality, and safety of vehicles in the U.S. Overall, this large amount of information is illuminating, but given some of the criticisms leveled at both sources, there is a viable concern about how much value should be placed on it. However, the consistency of the methodology used by both entities provides a foundation for a study of improvement in the factors of reliability, quality, and safety for vehicles. In particular, a comparison of how U.S. vehicles have improved over the last decade compared to those from the Far East competitors would be illuminating.

Our study compares the vehicles' scores from the two sources simultaneously in several dimensions of quality and reliability. Information derived from all of these dimensions shed light on the current state of that vehicle's overall quality. The dimensions which are scored and evaluated as critical contributors to quality are: Performance, comfort and convenience features, predicted reliability, safety (results of crash tests), dependability history (powertrain, body and interior, feature and accessory, and overall dependability), overall performance and design, and initial quality evaluation.

The combined data from CR and JDP will provide a good foundation for a meaningful comparison of the U.S. and Asian automobile manufacturers. As shown in this work, both sources provide current and historical data that can be utilized for direct comparisons and trend analysis. This analysis will ultimately address the need for fact-based understanding of how the U.S. and Asian automobile makers are performing in quality, reliability, and safety. Our analysis, which clearly describes the various aspects of the automobile that are currently covered by both JDP and CR, may pave the way for inclusion of other aspects not currently studied in future reports but considered important by consumers and manufacturers. A follow-on paper will discuss whether there are any correlations between the results found from these sources, what the trends exist in the three categories over time, and whether U.S. automakers are closing the gap with their Asian counterparts.

\section{References}

About us, Our mission, ConsumerReports.org. Consumers Union. Retrieved from http://www.consumerreports.org/cro/aboutus/mission/overview/index.htm

About Us, JDPower.com, [2011]. The McGraw Hill Companies. Retrieved from http://www.jdpower.com/about

Bradsher, Keith [2000, June 16]. Efficiency on Wheels; U.S. Auto Industry Is Catching Up With the Japanese. The New York Times. Retrieved from http://www.nytimes.com/2000/06/16/business/efficiency-on-wheels-us-auto-industry-is-catching-up-with-the-japanese.html

Car buying advice, Compare reliability for new cars, ConsumerReports.org. [2011]. Consumers Union. Retrieved from http://www.consumerreports.org/cro/cars/car-buying-advice/guide-to-new-car-buying/-narrow-your-choices/reliabilityinformation/index.htm

ConsumerReports.org. Consumers Union. (2006). New Cars. Crash test 101-How crash worthiness is measured and how crash ratings can help you choose your next car. Retrieved from http://www.consumerreports.org/cro/cars/new-cars/news/2006/crash-test-101-understanding-tests-and-ratings-1106/overview/0611_crash-test-101.htm

Dodge, John [2007]. Consumer Report's clout with autos. Design News, 62. Retrieved from http://libproxy.mst.edu:2048/login?url=http://proquest.umi.com/pqdweb?did=1305157501\&Fmt=3\&clientId= 23112\&RQT=309\&VName=PQD

FAQs, General Questions, JDPower.com, [2011]. The McGraw Hill Companies. Retrieved from http://www.jdpower.com/faqs

Flint, Jerry [2005, March 1]. Don’t dismiss Consumer Reports. Ward's Auto World. Retrieved from http://www.lexisnexis.com.libproxy.mst.edu/hottopics/lnacademic/?shr=t\&csi=254312\&sr=HLEAD [Don't+Dismiss+Consumer+Reports]+and+date+is+March, $\% 202005$ 
Ford wins most awards in J.D. Power APEAL study on vehicles that excite and satisfy.[n.d]. Retrieved from http://www.prnewswire.com/news-releases/ford-wins-most-awards-in-jd-power-apeal-study-on-vehicles-that-excite-andsatisfy-98524329.html

History Repeats -- Porsche Ranks Highest in J.D. Power and Associates' APEAL Study Again! [n.d]. Retrieved from http://www.prnewswire.com/news-releases/history-repeats----porsche-ranks-highest-in-jd-power-and-associates-apealstudy-again-98527719.html

Korsch, David [2007, March 23]. Consumer Reports auto objectivity questioned. North Shore News. Retrieved from http://www.lexisnexis.com.libproxy.mst.edu/hottopics/lnacademic/?shr=t\&csi=296068\&sr=HLEAD [Consumer+Reports'+auto+objectivity+questioned]+and+date+is+March,\%202007

Murray, Charles J. [2007]. Consumers talk back. Design News, 62. Retrieved from http://libproxy.mst.edu:2048/login?url=http://proquest.umi.com/pqdweb?did=1305157531\&Fmt=3\&clientId= 23112\&RQT $=309 \&$ VName=PQD

Newman, Richard J. [2004, March 7]. Ratings ruler seeks subjects. U.S. News \& World Report. Retrieved from

http://www.usnews.com/usnews/biztech/articles/040315/15eepower_2.htm

Noah, Timothy [1999, August 8]. People’s choice awards. The New York Times. Retrieved from http://www.nytimes.com/1999/08/08/magazine/people-s-choice-awards.html?pagewanted=all\&src=pm

Snyder, Jesse [2009, June 23]. J.D. Power Initial Quality Survey defeats itself. Retrieved from http://www.autonews.com/article/20090623/BLOG03/906239976

Whitney, Tony [2001, December 14]. What is your car's APEAL?: J.D. Power ratings define from the manufacturer's point of view of what consumers want. The Vancouver Sun. Retrieved from http://www.lexisnexis.com.libproxy.mst.edu/hottopics/lnacademic/?shr=t\&csi=8370\&sr=HLEAD

[What+is+your+car's+APEAL\%3F]+and+date+is+December,\%202001

\section{Biographical notes}

Dr. Elizabeth Cudney is an Assistant Professor at Missouri University of Science and Technology. She received her B.S. in Industrial Engineering from North Carolina State University, Master of Engineering in Mechanical Engineering and Master of Business Administration from the University of Hartford, and her doctorate in Engineering Management from the University of Missouri - Rolla. In 2010, Dr. Cudney was inducted into the ASQ International Academy for Quality. She received the 2008 ASQ A.V. Feigenbaum Medal and the 2006 SME Outstanding Young Manufacturing Engineering Award. She is an ASQ Certified Quality Engineer, Manager of Quality/Operational Excellence, and Certified Six Sigma Black Belt. She is a member of the ASEE, ASEM, ASME, ASQ, IIE, SAE, and the Japan Quality Engineering Society (JQES).

Ozge Senoz, William Daughton and Abhijit Gosavi are of Missouri University of Science and Technology.

Received January 2011

Accepted June 2011

Final acceptance in revised form June 2011 